\title{
Investigations on the 1,2-Hydrogen Atom Transfer Reactivity of Alkoxyl Radicals under Visible-Light-Induced Reaction Conditions
}

\author{
Dan Liu ${ }^{\mathrm{a}}$ \\ Jing Zhang \\ Yiyun Chen ${ }^{* a, b}$ \\ a State Key Laboratory of Bioorganic and Natural Products Chemistry, \\ Center for Excellence in Molecular Synthesis, Shanghai Institute of \\ Organic Chemistry, University of Chinese Academy of Sciences, \\ Chinese Academy of Sciences, 345 Lingling Road, Shanghai \\ 200032, P. R. of China \\ ${ }^{b}$ School of Chemistry and Material Sciences, Hangzhou Institute for \\ Advanced Study, University of Chinese Academy of Sciences, \\ 1 Sub-lane Xiangshan, Hangzhou 310024, P. R. of China
}

Published as part of the Cluster Radicals - by Young Chinese Organic Chemists

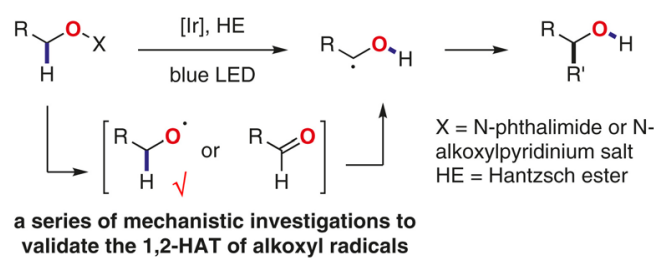

for the new $\mathrm{C}-\mathrm{C}$ bond formations. ${ }^{4}$ We describe our journey in this Account on the 1,2-HAT reactivity discovery for the selective $\alpha-\mathrm{C}-\mathrm{H}$ functionalization by alkoxyl radicals, which have spanned over several years in retrospect when we first discovered alkoxyl-radical generation under visible-lightinduced reaction conditions in $2015.5^{5}$ We have performed various mechanistic investigations to validate the existence of alkoxyl-radical 1,2-HAT reactivity, and will describe them in detail in this Account.

$$
\begin{aligned}
& \text { a) Hydrogen-atom transfer by the alkoxyl radical: intermolecular } \\
& \mathrm{HAT}, 1,5-\mathrm{HAT} \text { (well-studied), and 1,2-HAT (little-known) } \\
& \text { (well-studied) } \\
& \text { (well-studied) }
\end{aligned}
$$

b) Visible-light-induced reactions of $\mathrm{N}$-alkoxyphthalimides

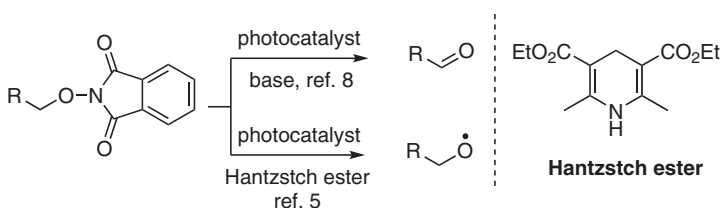

c) Three key questions on the 1,2-HAT reactivity of alkoxyl radicals

$$
\begin{aligned}
& \mathrm{H}_{\mathrm{H}}^{\mathrm{R}} \underset{\text { blue LED }}{\stackrel{[\mathrm{Ir}], \mathrm{HE}}{\longrightarrow}}{ }^{\mathrm{R}} \underset{\mathrm{H}}{\mathrm{O}} \stackrel{\text { 1,2-HAT }}{\longrightarrow} \mathrm{R}^{\mathrm{O}} \mathrm{O}_{{ } \mathrm{H}} \\
& \text { phth }=\text { phthalimide } \\
& \text { - Could aldehydes/ketones be the sole reaction intermediate? } \\
& \text { - Is the alkoxyl radical absolutely involved? } \\
& \text { - Does the 1,2-HAT of alkoxyl radicals irrefutably exist? }
\end{aligned}
$$

Scheme 1 The investigation of the alkoxyl-radical HAT reactivity 
$N$-Alkoxylphthalimides are stable on the benchtop and can be easily prepared from alcohols or alkyl halides. ${ }^{6}$ The traditional heating conditions with azodiisobutyronitrile/tributyltin hydride generated alkoxyl radicals from $\mathrm{N}$ alkoxylphthalimides, ${ }^{6,7}$ however, the relatively harsh reaction conditions limited the functional group compatibility and further synthetic applications. The first attempt to generate alkoxyl radicals from $\mathrm{N}$-alkoxylphthalimides under visible-light-induced reaction conditions was conducted in 2011 , however, only the aldehydes were obtained by the intramolecular redox fragmentations, and the alkoxyl radical was not observed (Scheme 1b). ${ }^{8}$ In 2015 the first alkoxylradical generation under visible-light-induced reaction conditions from $\mathrm{N}$-alkoxylphthalimides was reported by our group, and the use of Hantzsch ester (HE) was critical for the alkoxyl-radical generation. ${ }^{5}$ The alkoxyl radicals generated under visible-light-induced reaction conditions from $N$-alkoxylphthalimides and HE have demonstrated various 1,5 -HAT and $\beta$-fragmentation reactivity with excel- lent chemoselectivity and functional group compatibility, ${ }^{9}$ which are suitable for the late-stage functionalization of complex alcohol molecules with excellent regioselectivity.

In 2019, our group reported the first regioselective $\alpha$ $\mathrm{C}\left(\mathrm{sp}^{3}\right)-\mathrm{H}$ allylation of $\mathrm{N}$-alkoxylphthalimides under visiblelight-induced reaction conditions, and the 1,2-HAT of alkoxyl radicals was proposed as the reaction mechanism. ${ }^{10}$ However, some key questions remained to be conclusively addressed in the preliminary communication. In this Account, we will discuss three key questions regarding the proposed reaction mechanism (Scheme 1c): 1) May the aldehyde/ ketone be the sole reaction intermediate? 2) Is the alkoxyl radical absolutely involved? 3) Does the 1,2-HAT of alkoxyl radical irrefutably exist? As the reaction optimization and substrate scopes have been revealed in the previous communication, ${ }^{10}$ we will briefly summarize them and will not report the whole dataset in detail (Scheme 2). In brief, the $\alpha$-carbonyl, $\alpha$-cyano, $\alpha$-trifluoromethyl, and ben-

\section{Biographical Sketches \\ Dan Liu was born in 1993 in Yangzhou, P. R. of China. She re- ceived her Bachelor's degree in \\ chemistry from Soochow Uni- versity (P. R. of China) in 2016, after which she joined Professor \\ Chen's group to pursue PhD studies on the visible-light-in- duced rearrangement reactions.}
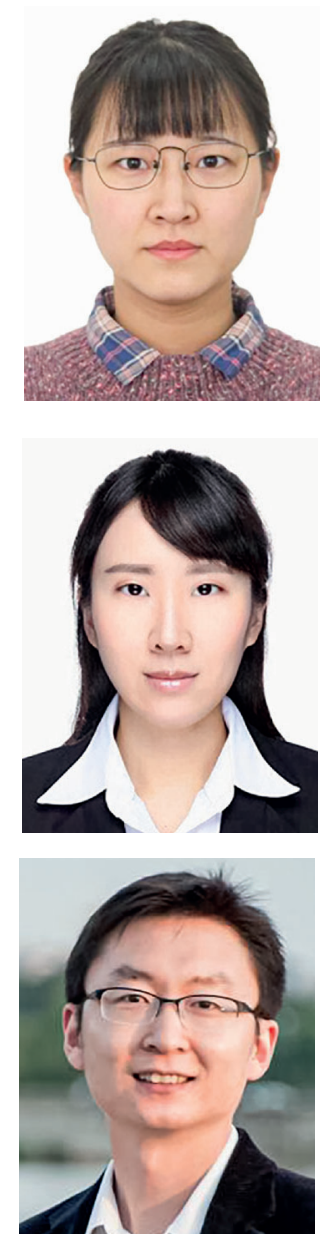

Dr. Jing Zhang was born in 1989 in Tianjin, P. R. of China. She received her Bachelor's degree in chemistry at Sichuan
University ( $P$. R. of China) in 2012 and earned her Master's and PhD degrees in organic chemistry in Professor Chen's group at Shanghai Institute of Organic Chemistry, Chinese Academy of Sciences in 2018.
Dr. Yiyun Chen received his Bachelor's degree in chemistry at Peking University (P. R. of China) in 2002 and earned his $\mathrm{PhD}$ degree in organic chemistry at Princeton University (USA) in 2007. After postdoctoral studies at Harvard University (USA) and Howard Hughes Med- ical Institute (USA), he joined Shanghai Institute of Organic Chemistry, Chinese Academy of Sciences (P. R. of China) as a Principle Investigator in 2011, with the research interest on developing novel biocompatible light-induced chemical methods to study biology, including new light-induced reaction discovery and new optochemical biology tool development. Chen is on the editorial board of ChemPhotoChem and the advisory editorial board of Organic Chemistry Frontiers. 
zylic $\mathrm{N}$-alkoxylphthalimides were suitable substrates for the $\alpha-\mathrm{C}-\mathrm{H}$ allylation (4-13), and the photocatalyst in combination with $\mathrm{HE}$ was required for the reaction.

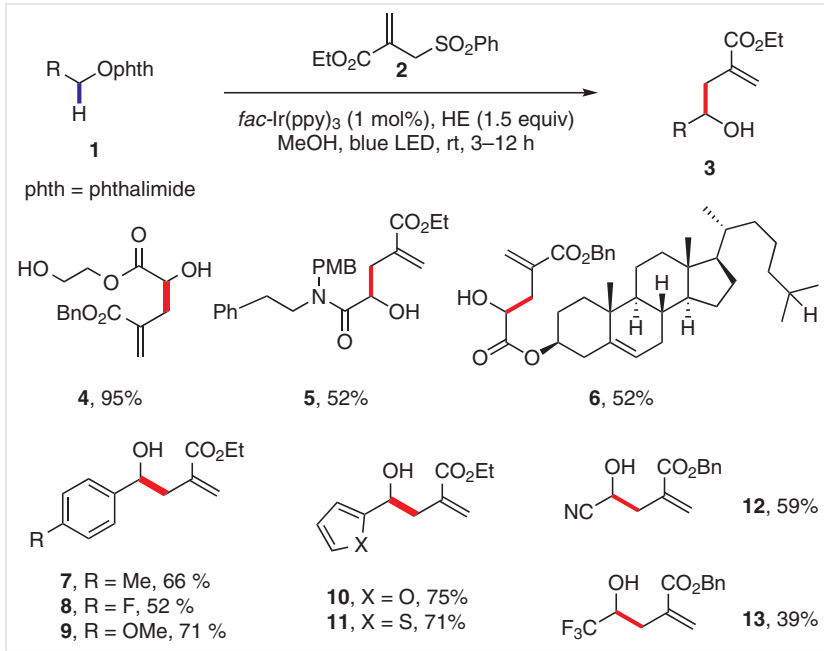

Scheme 2 The substrate scope of $\mathrm{N}$-alkoxylphthalimides for the $\alpha-\mathrm{C}-\mathrm{H}$ allylation. Reagents and conditions: 1 ( $0.10 \mathrm{mmol}, 1.0$ equiv), 2 (0.30 mmol, 3.0 equiv), fac-Ir(ppy $)_{3}(0.001 \mathrm{mmol}, 1 \%)$, and Hantzsch ester ( $0.15 \mathrm{mmol}, 1.5$ equiv) in $1.0 \mathrm{~mL} \mathrm{MeOH}$ under nitrogen atmosphere with $4 \mathrm{~W}$ blue LED irradiation at ambient temperature for 3-12 h.

\section{Could Aldehydes/Ketones Be the Sole Re- action Intermediate for the $\alpha-\mathrm{C}-\mathrm{H}$ Allylation? NO}

The initial mechanistic investigation on the 1,2-HAT of alkoxyl radicals was complicated by the NMR analysis on the reaction mixture of $N$-alkoxylphthalimide 14, in which the formation of keto ester $\mathbf{1 6}$ was observed (Scheme 3a). With the consumption of $\mathrm{N}$-alkoxylphthalimide $\mathbf{1 4}$ and the formation of allylation product 15 , the keto ester 16 was detected as well, however, in less than $5 \%$ yield. This observation raised the question if the keto ester $\mathbf{1 6}$ was the sole reaction intermediate leading to the $\alpha-\mathrm{C}-\mathrm{H}$ allylation product $\mathbf{1 5}$ and the alkoxyl-radical intermediate was not involved. In fact, our group had previously reported the polarity-reversed allylation of aldehydes or ketones under similar visible-light-induced reaction conditions. ${ }^{11}$ To add more convolution to the mechanistic investigation, the injection of keto ester $\mathbf{1 6}$ to the reaction conditions above resulted in the formation of $\mathbf{1 5}$ in $\mathbf{7 3 \%}$ isolated yield (Scheme 3b). All these results brought the first key question to the table: May the aldehyde/ketone be the sole reaction intermediate for the $\alpha$ $\mathrm{C}-\mathrm{H}$ allylation without involving the 1,2-HAT of alkoxyl radicals?

Based on the literature and our own mechanistic studies, there are two mechanistic scenarios for $\mathrm{N}$-alkoxylphthalimides upon the single-electron reduction of $N$-alkoxylphthalimides under visible-light-induced reaction condi-

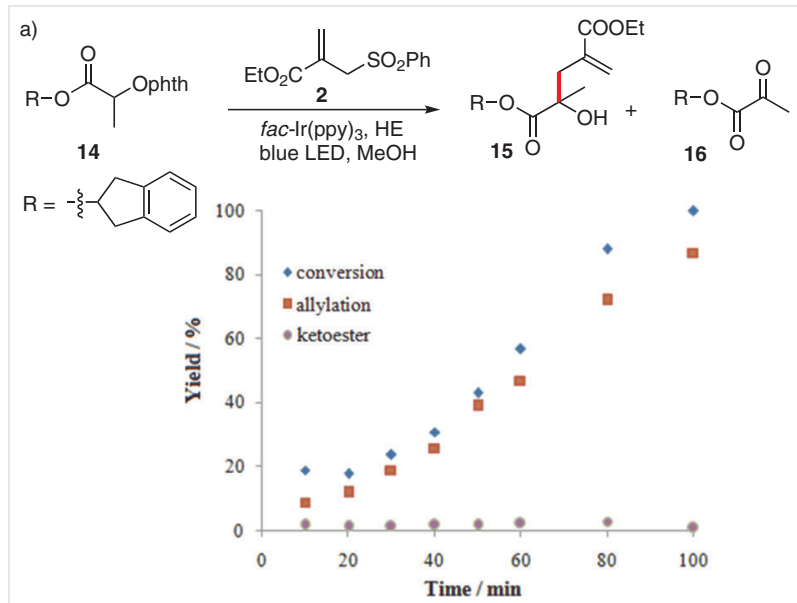

b)<smiles>CC(=O)C(=O)OC1Cc2ccccc2C1</smiles>

reaction conditions above 16

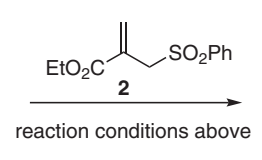

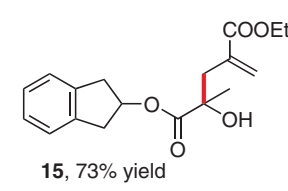

$15,73 \%$ yield
Scheme 3 The keto ester was observed in the reaction conditions of $\mathrm{N}$-alkoxylphthalimides and could engage in the allylation reaction. Reagents and conditions: 14 (0.30 mmol), 2 (0.90 mmol), HE (0.45 mmol) in $3.0 \mathrm{~mL} \mathrm{MeOH}$ under nitrogen with $4 \mathrm{~W}$ blue LED irradiation at ambient temperature; phth $=$ phthalimide.

tions (Scheme 4a): $i$ ) in the presence of bases, the concerted intramolecular elimination of benzyl-substituted $N$-alkoxylphthalimide yields the aldehyde $\mathbf{C} ;{ }^{8}$ and $i i$ in the presence of Hantzsch ester, the single-electron reduction and protonation by HE yields the alkoxyl radical $\mathbf{A} .{ }^{5}$ The paradox lies upon if the $\alpha$-C-centered radical $\mathbf{B}$ is the result of the single-electron reduction from the aldehyde $\mathbf{C}$ or the 1,2HAT adduct from the alkoxy radical $\mathbf{A}$. To address this, we have synthesized $\mathrm{N}$-alkoxylphthalimide $\mathbf{1 7}$ and subjected it to the reaction conditions (Scheme $4 \mathrm{~b}$ ). The $\alpha-\mathrm{C}-\mathrm{H}$ allylation adduct 18 was obtained in $18 \%$ yield with 1,4-diazabicyclo(2,2,2)octane (DABCO) and formic acids addition to accelerate the reaction. In contrast, no allylation product was obtained from aldehyde $\mathbf{1 9}$, which confirmed that the carbonyl compound was not the sole reaction intermediate leading to the $\alpha-\mathrm{C}-\mathrm{H}$ radical formation and the alkoxyl radical had to be involved. The enantiopure $(R)-N$-alkoxylphthalimide $\mathbf{2 0}$ was also subjected to the reaction conditions with thiophenol $\mathbf{2 1}$ as the hydrogen donor to obtain the alcohol, and the reduced alcohol adduct $\mathbf{2 2}$ was obtained with the $R / S$ ratio $=79: 21$ in $>95 \%$ yield (Scheme $4 \mathrm{c}$ ). This result suggested the keto ester $\mathbf{1 6}$ was not the sole reaction intermediate which would lead to the achiral alcohol product, and the alkoxyl radical need to be involved for the chiral alcohol formation. In addition, the $\alpha$-cyano- or $\alpha$-trifluoromethyl-substituted $N$-alkoxylphthalimides afforded the $\alpha-\mathrm{C}-\mathrm{H}$ allylation products $\mathbf{1 2}$ and $\mathbf{1 3}$ in 59\% and 39\% yields, respectively (Scheme $4 \mathrm{~d}$ ). In contrast, their counterpart 
formyl cyanide $\mathbf{2 3}$ and trifluoromethyl aldehyde $\mathbf{2 4}$ were extremely unstable molecule moieties to be synthetically utilized. Taken together, a negative answer is obtained for the aldehyde/ketone as the sole reaction intermediate for the $\alpha-\mathrm{C}-\mathrm{H}$ allylation and the presence of the alkoxyl radical is required.

a)

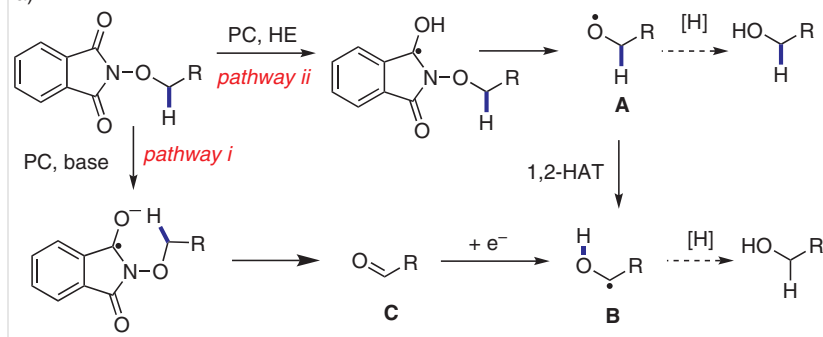

b)

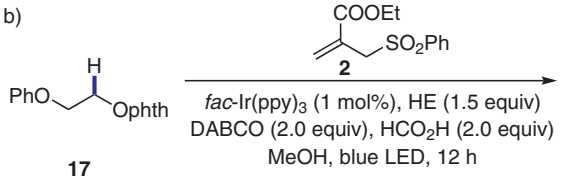

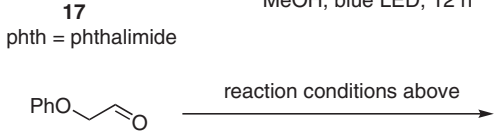

19

20

d)<smiles>C[C@H](OP)C(=O)OC1Cc2ccccc2C1</smiles>

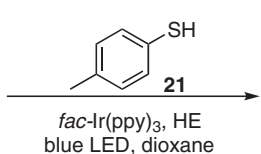

blue LED, dioxane

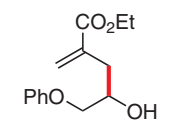

$18,<5 \%$

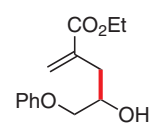

$18,18 \%$

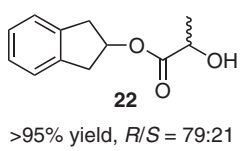

$>95 \%$ yield, $R / S=79: 21$

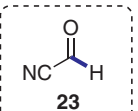

23
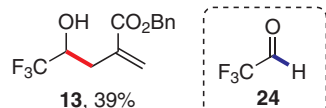

Scheme 4 The experimental evidence to exclude the aldehyde/ ketone as the sole reaction intermediate for the $\alpha-\mathrm{C}-\mathrm{H}$ allylation

\section{Is the Alkoxyl Radical Absolutely Involved in the Reaction? YES}

The second question is if the presence of alkoxyl radicals could be experimentally validated in the reaction conditions. In fact, the electron paramagnetic resonance (EPR) experiment with 5,5-dimethyl-pyrroline $\mathrm{N}$-oxide (DMPO) $\mathbf{2 6}$ as the radical spin trap detected both the O-centered radical trapping adduct $\mathbf{2 7}$ and the $\alpha$-C-centered radical trapping adduct $\mathbf{2 8}$, which directly confirmed the existence of the alkoxyl radical (Scheme 5a). ${ }^{10}$ The presence of the alkoxyl radical could also be validated by the well-studied reactivity of alkoxyl radicals by the probe molecules $\mathbf{2 9}$ and 32. The $N$-alkoxylphthalimide 29 has both the $\delta-\mathrm{C}-\mathrm{H}$ and $\alpha-$ $\mathrm{C}-\mathrm{H}$ that are prone to the intramolecular HAT, and the $\delta-\mathrm{C}-$ $\mathrm{H}$ allylation adduct $\mathbf{3 1}$ could be obtained in 53\% yield, together with the $\alpha-\mathrm{C}-\mathrm{H}$ allylation adduct $\mathbf{3 0}$ in $28 \%$ yield

(Scheme 5b). With the pendent alkene at the $\delta$-position of the $\mathrm{N}$-alkoxylphthalimide, the 5-exo-cyclization adduct $\mathbf{3 3}$ was obtained in $62 \%$ yield, while the ketone 34 was not observed (Scheme 5c). These results from EPR experiments and probe molecules validated the existence of alkoxyl radicals in the reaction conditions and excluded the aldehydes/ketones as the sole reaction intermediates.
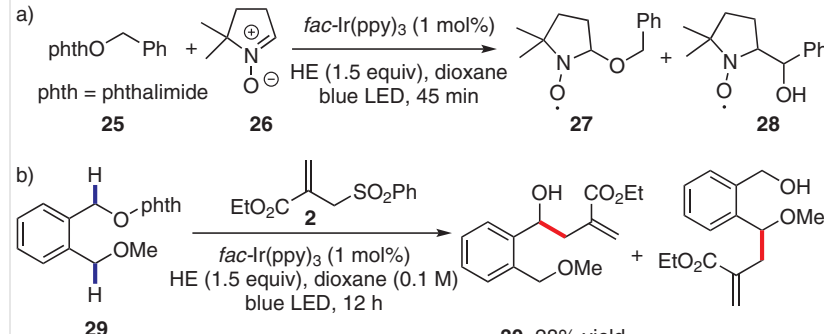

$$
\text { c) }
$$

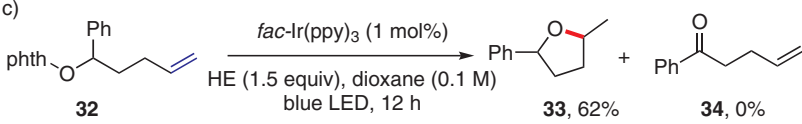

Scheme 5 The evidence of the presence of alkoxyl radicals in the reaction conditions

The intermolecular HAT pathway to afford the $\alpha$-C-centered radical was next evaluated by the crossover experiments (Scheme 6). The naphthalenylmethanol $\mathbf{3 6}$ and the structurally similar $N$-alkoxylphthalimide 35 were subjected to the standard reaction conditions with allylsulfone $\mathbf{2}$ (Scheme 6a). The homoallylic alcohol 7 from 35 was obtained in 69\% yield, while the homoallylic alcohol 37 from 36 was not observed. This result excluded the alcohol formation from the hydrogenation of the alkoxyl radical and the subsequent intermolecular HAT on the $\alpha-\mathrm{C}-\mathrm{H}$ of the alcohol. The $\mathbf{N}$-alkoxylsuccinimide $\mathbf{3 8}$ was further tested which succinimide moiety has the similar electronic property as the phthalimide moiety. As a result, only the formation of 37 from 39 was obtained in $44 \%$ yield, and the $N$ alkoxylsuccinimide $\mathbf{3 8}$ was recovered in $>95 \%$ yield. Taken together, the intermolecular HAT does not contribute to the $\alpha-\mathrm{C}-\mathrm{H}$ allylation of $\mathrm{N}$-alkoxylphthalimides.

\section{Does the 1,2-HAT of Alkoxyl Radicals Irre- futably Exist? YES}

With the negative answer for the carbonyl compound as the sole reaction intermediate and the positive answer for the alkoxyl-radical presence in the reaction conditions, the final and most essential question is if the 1,2-HAT of alkoxyl radical irrefutably exists? While the 1,2-HAT of alkoxyl radicals under visible-light-induced reaction conditions was first revealed with $\mathrm{N}$-alkoxylphthalimides as radical precursors, ${ }^{10,12}$ the carbonyl compound formation in the reaction conditions complicated the mechanistic analysis. We envi- 
<smiles>Cc1ccc(COP)cc1</smiles>
36

b)

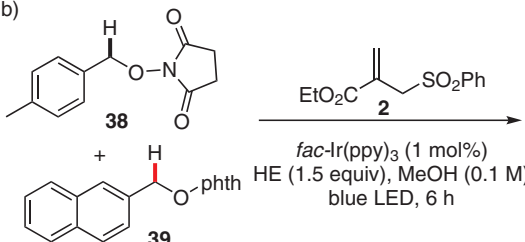

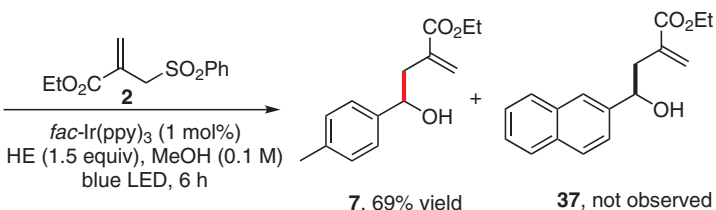

phth $=$ phthalimide<smiles>C=C(CC)CC(O)c1ccc2ccccc2c1</smiles>

38, $>95 \%$

Scheme 6 The experimental evidence to exclude the intermolecular HAT reaction

sion the demonstration of 1,2-HAT reactivity from other alkoxyl-radical precursors, especially in the absence of the carbonyl intermediate, will irrefutably validate the unusual 1,2-HAT reactivity of alkoxyl radicals. The $N$-alkoxylpyridinium salt has been shown to generate alkoxyl radicals under visible-light-induced reaction conditions, and there were no redox fragmentation pathways to form aldehydes or ketones. ${ }^{13}$ In addition, various 1,5 -HAT or alkene addition reactivity of $N$-alkoxylpyridinium salts have been reported to validate the alkoxyl-radical generation. ${ }^{14}$

We then synthesized the $N$-alkoxylpyridinium salt 40 derived from the $\alpha$-hydroxyl ester and subjected it to the standard reaction conditions (Scheme 7a). While the use of HE was not required for the previous alkoxyl-radical generation from $N$-alkoxylpyridinium salts, it has been proved useful for the reductive coupling reactions with allyl sulfones. 5,9b,11,15 Throughout the reaction courses, no methyl 2oxoacetate $\mathbf{4 3}$ was observed, in sharp contrast to the reactions using $N$-alkoxylphthalimides. Instead, the $\alpha-\mathrm{C}-\mathrm{H}$ al-

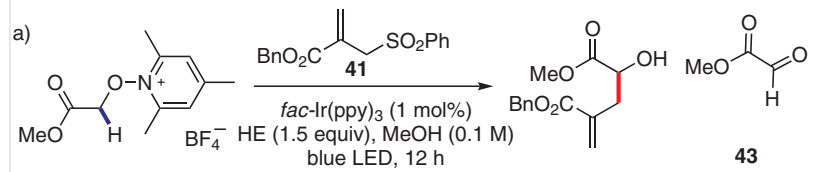

40 42, $61 \%$ yield not observed

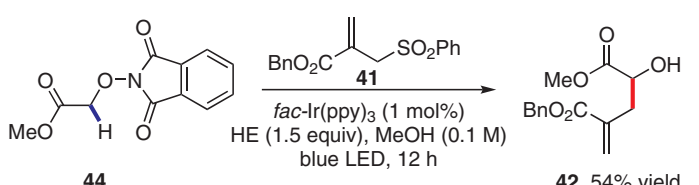

44 blue LED, $12 \mathrm{~h}$

42, $54 \%$ yield

b)

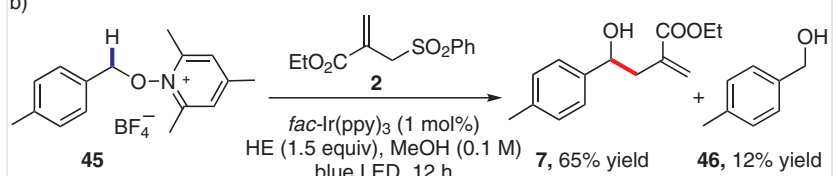

45 blue LED, 12 h

Scheme 7 The alkoxyl-radical 1,2-HAT reactivity from $N$-alkoxylpyridium salts lylation adduct $\mathbf{4 2}$ was obtained in $61 \%$ yield, which was comparable to the $54 \%$ yield from $\mathrm{N}$-alkoxylphthalimide $\mathbf{4 4}$ derived from the same $\alpha$-hydroxyl ester. The $N$-alkoxylpyridinium salt derivatives of benzyl alcohol $\mathbf{4 5}$ also afforded the $\alpha-\mathrm{C}-\mathrm{H}$ allylation adduct 7 in $65 \%$ yield together with the hydrogenation adduct 46 in 12\% yield (Scheme 7b), which were comparable to the reactions of $N$-alkoxylphthalimides to obtain 66\% yield of 7 in Scheme 2. These results collectively suggested the 1,2-HAT of alkoxyl radicals universally existed and was independent on the radical precursors used.

From the mechanistic investigations on the above three key questions, we propose the reaction is initiated from the reductive quenching of the photoexcited $\operatorname{Ir}(\mathrm{III})^{*}$ to $\operatorname{Ir}(\mathrm{II})$ by Hantzsch ester, and Ir(II) subsequently reduces the $N$-alkoxylphthalimide or the $N$-alkoxylpyridinium salt to the radical anion (Scheme 8). The radical anion then undergoes proton transfer with Hantzsch ester radical cation and subsequent $\mathrm{N}-\mathrm{O}$ bond cleavage to form the alkoxyl radical, which subsequently undergoes 1,2 -HAT and allylation reaction. In the case of $\mathrm{N}$-alkoxylphthalimides, the carbonyl compound intermediate cannot be excluded; however, the alkoxyl radical irrefutably exists with the 1,2-HAT reactivity. In the case of $\mathrm{N}$-alkoxylpyridinium salts, the 1,2-HAT reactivity of the

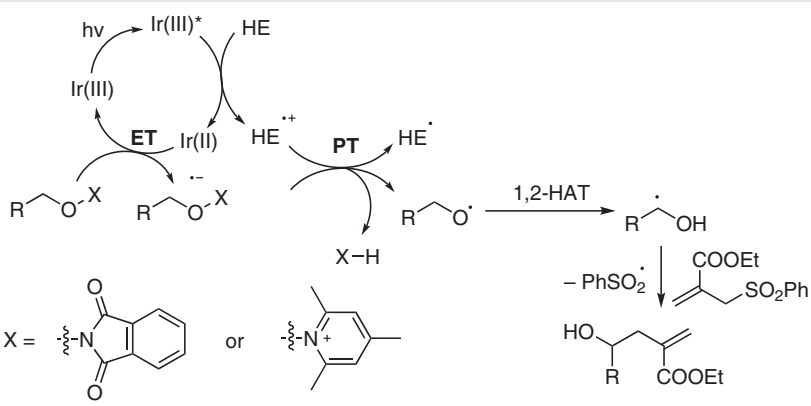

Scheme 8 The mechanistic proposal of the alkoxyl-radical 1,2-HAT reactivity 
alkoxyl radical is the only irrefutable reaction pathway leading to the $\mathrm{C}-\mathrm{H}$ allylation products.

\section{Conclusion}

In conclusion, we have investigated the 1,2-HAT reactivity of alkoxyl radicals under visible-light-induced reaction conditions and unambiguously addressed three key questions for the reaction mechanism: i) The aldehydes/ketones as the sole reaction intermediate was excluded by the $\alpha-C-$ $\mathrm{H}$ allylations on substrates requiring the alkoxyl-radical intermediates and the retention of the chiral information from the enantiopure substrate. ii) The presence of alkoxyl radicals in the reaction conditions was experimentally validated by EPR studies with the radical spin trap and the signature reactivity of alkoxyl radicals; and the intermolecular HAT pathways were excluded by the crossover experiments. iii) The $\alpha-\mathrm{C}-\mathrm{H}$ allylation by $\mathrm{N}$-alkoxylpyridinium salts suggested the alkoxyl-radical 1,2-HAT reactivity was independent on the alkoxyl-radical precursors and irrefutably validated its existence.

\section{Funding Information}

Financial support was provided by the National Natural Science Foundation of China $(91753126,21622207)$ and Strategic Priority Research Program of the Chinese Academy of Sciences (XDB20020200).

\section{Acknowledgment}

We thank the Chen group members for helpful suggestions in preparing this Account.

\section{Supporting Information}

Supporting information for this article is available online at https://doi.org/10.1055/a-1300-3453.

\section{References}

(1) (a) Surez, E.; Rodriguez, M. S. In Radicals in Organic Synthesis, Vol. 2; Philippe, R.; Sibi, M. P., Ed.; Wiley-VCH: Weinheim, 2001, 440. (b) Cekovic, Z. J. Serb. Chem. Soc. 2005, 70, 287. (c) Chiba, S.; Chen, H. Org. Biomol. Chem. 2014, 12, 4051.
(2) Blanksby, S. J.; Ellison, G. B. Acc. Chem. Res. 2003, 36, 255.

(3) (a) Barton, D. H. R.; Beaton, J. M.; Geller, L. E.; Pechet, M. M. J. Am. Chem. Soc. 1960, 82, 2640. (b) Barton, D. H. R.; Beaton, J. M.; Geller, L. E.; Pechet, M. M. J. Am. Chem. Soc. 1961, 83, 4076.

(4) Salamone, M.; Bietti, M. Acc. Chem. Res. 2015, 48, 2895.

(5) Zhang, J.; Li, Y.; Zhang, F.; Hu, C.; Chen, Y. Angew. Chem. Int. Ed. 2016, 55, 1872.

(6) Kim, S.; Lee, T. A.; Song, Y. Synlett 1998, 471.

(7) (a) Martín, A.; Rodríguez, M. S.; Suárez, E. Tetrahedron Lett. 1999, 40, 7525. (b) Sartillo-Piscil, F.; Vargas, M.; Anaya de Parrodi, C.; Quintero, L. Tetrahedron Lett. 2003, 44, 3919. (c) Martín, A.; Quintanal, L. M.; Suárez, E. Tetrahedron Lett. 2007, 48, 5507. (d) Martín, A.; Pérez-Martín, I.; Quintanal, L. M.; Suárez, E. Tetrahedron Lett. 2008, 49, 5179. (e) Hernández-García, L.; Quintero, L.; Sánchez, M.; Sartillo-Piscil, F. J. Org. Chem. 2007, 72, 8196. (f) Francisco, C. G.; León, E. I.; Martín, A.; Moreno, P.; Rodríguez, M. S.; Suárez, E. J. Org. Chem. 2001, 66, 6967. (g) Zlotorzynska, M.; Zhai, H.; Sammis, G. M. Org. Lett. 2008, 10, 5083. (h) Zhu, H.; Wickenden, J. G.; Campbell, N. E.; Leung, J. C. T.; Johnson, K. M.; Sammis, G. M. Org. Lett. 2009, 11, 2019. (i) Sánchez-Eleuterio, A.; Quintero, L.; Sartillo-Piscil, F. J. Org. Chem. 2011, 76, 5466. (j) Rueda-Becerril, M.; Leung, J. C. T.; Dunbar, C. R.; Sammis, G. M. J. Org. Chem. 2011, 76, 7720. (k) Zhu, H.; Leung, J. C. T.; Sammis, G. M. J. Org. Chem. 2015, 80, 965.

(8) Zlotorzynska, M.; Sammis, G. M. Org. Lett. 2011, 13, 6264.

(9) (a) Wang, C.; Harms, K.; Meggers, E. Angew. Chem. Int. Ed. 2016, 55, 13495. (b) Zhang, J.; Li, Y.; Xu, R.; Chen, Y. Angew. Chem. Int. Ed. 2017, 56, 12619. (c) Ito, Y.; Kimura, A.; Osawa, T.; Hari, Y. J. Org. Chem. 2018, 83, 10701. (d) Han, J. B.; Guo, A.; Tang, X. Y. Chem. Eur. J. 2019, 25, 2989. (e) Shi, J. L.; Wang, Z;; Zhang, R.; Wang, Y.; Wang, J. Chem. Eur. J. 2019, 25, 8992.

(10) Zhang, J.; Liu, D.; Liu, S.; Ge, Y.; Lan, Y.; Chen, Y. iScience 2020, 23, 100755.

(11) Qi, L.; Chen, Y. Angew. Chem. Int. Ed. 2016, 55, 13312.

(12) Zhong, L. J.; Wang, H. Y.; Ouyang, X. H.; Li, J. H.; An, D. L. Chem. Commun. 2020, 56, 8671.

(13) (a) Capaldo, L.; Ravelli, D. Chem. Commun. 2019, 55, 3029. (b) He, F.-S.; Ye, S.; Wu, J. ACS Catal. 2019, 9, 8943. (c) Rossler, S. L.; Jelier, B. J.; Magnier, E.; Dagousset, G.; Carreira, E. M.; Togni, A. Angew. Chem. Int. Ed. 2020, 59, 9264.

(14) (a) Kim, I.; Park, B.; Kang, G.; Kim, J.; Jung, H.; Lee, H.; Baik, M. H.; Hong, S. Angew. Chem. Int. Ed. 2018, 57, 15517. (b) Bao, X.; Wang, Q.; Zhu, J. Chem. Eur. J. 2019, 25, 11630. (c) Bao, X.; Wang, Q.; Zhu, J. Angew. Chem. Int. Ed. 2019, 58, 2139. (d) Barthelemy, A. L.; Tuccio, B.; Magnier, E.; Dagousset, G. Angew. Chem. Int. Ed. 2018, 57, 13790. (e) Barthelemy, A.-L.; Tuccio, B.; Magnier, E.; Dagousset, G. Synlett 2019, 30, 1489. (f) Kim, Y.; Lee, K.; Mathi, G. R.; Kim, I.; Hong, S. Green Chem. 2019, 21, 2082.

(15) Hu, C.; Chen, Y. Org. Chem. Front. 2015, 2, 1352. 